\title{
Understanding the ROC Transfer Payment in the Renewable Obligation with the Recycling Mechanism in the United Kingdom
}

\author{
Jinke $\mathrm{Li}^{1}$, Guy Liu ${ }^{2} *$, Jing Shao ${ }^{1}$ \\ ${ }^{1}$ School of Management, Swansea University, the United Kingdom \\ ${ }^{2}$ Peking University HSBC Business School, Peking University, China
}

\begin{abstract}
The Renewable Obligation scheme was implemented to promote renewable energy for electricity supply in the UK over 15 years from 2002 to 2017. Renewable Obligation Certificates (ROCs) were allocated to accredited generators for receiving additional revenues from selling those certificates to electricity suppliers. In particular, a recycling mechanism was employed in this scheme. That is, the penalties on missing ROCs from all suppliers are paid into the buy-out fund, which is then redistributed to suppliers in proportion to the number of ROCs they presented. This mechanism complicated the ROC trading in three aspects. First, the recycling mechanism induces strategic behaviour between suppliers in fulfilling the obligation of purchase of ROCs, leading to the equilibrium of a lower transfer payment from suppliers to generators, compared with the scenario without the mechanism. Secondly, under the recycling mechanism, the existence of vertical integration encourages upstream competition between generators, reducing ROC prices and the transfer payment. Thirdly, suppliers may strategically collude with each other to take the advantage of the recycling mechanism, but the existence of vertical integration weakens the collusion and prevents the worst case of nearly zero transfer payment.
\end{abstract}

Key Words: Renewable Obligation, Recycling mechanism, Strategic behavior, Compliance, Vertical integration.

JEL code: C70, H32, L94, Q28, Q42, Q48

C70 Game Theory and Bargaining Theory

H32 Fiscal Policies and Behaviour of Economic Agents

L94 Electric Utilities

Q28 Renewable Resources and Conservation

Q42 Alternative Energy Sources

Q48 Government Policy

\footnotetext{
* Corresponding author. Email: liusj@phbs.pku.edu.cn. Address: PHBS UK, Foxcombe Hall, Boars hill, Oxford OX1 5HR

${ }^{1}$ This research did not receive any specific grant from funding agencies in the public, commercial, or not-for-profit sectors.
} 


\section{Introduction}

As growing attention has been given to climate change and carbon emission, many countries have implemented policies to support renewable energy in their electricity sector. There are mainly price-based policies, such as feed-in tariffs or premiums, and quantity-based policies, such as quota systems using tradable green certificates. A large amount of literature has been devoted to the assessment of the effectiveness of these systems (Menanteau et al., 2003; Meyer, 2003; Mitchell et al., 2006; Butler and Neuhoff, 2008; Fouquet and Johansson, 2008; Jacobsson et al., 2009; Haas et al., 2011; Ragwitz and Steinhilber, 2014; Winkler et al., 2016; Nicolini and Tavoni, 2017; Schallenberg-Rodriguez, 2017).

On one end of the spectrum, in a fixed feed-in tariff (FIT) system, electricity generators receive a fixed tariff for each unit of electricity they produce, and distribution network operators are obliged to accept this output to their network. This system is suitable for small-scale renewable and low-carbon electricity generation projects, such as the Feed-In Tariffs introduced in April 2010 in the UK for renewable sources producing up to 5 MW power. ${ }^{2}$ A more market-oriented variant of the FIT is known as the feed-in premium (FIP) system that has an extra margin (called the premium) added to the market price of electricity generators receive from the market. In both systems, the tariff or premium is usually set for a number of years, to provide the price security to investors for a substantial part of the project lifetime. The feed-in premium (FIP) system is in use in most European countries, such as Germany, Denmark, and Spain, in combination with other support instruments or as the main support system (Hvelplund, 2001; Lauber and Mez, 2004; Mitchell et al., 2006; del Río and Gual, 2007; Lipp, 2007; Meyer, 2007; del Río González, 2008; Lesser and Su, 2008; Munksgaard and Morthorst, 2008; Toke et al., 2008; Couture and Gagnon, 2010; Mabee et al., 2012; Schallenberg-Rodriguez and Haas, 2012; Jenner et al., 2013; Antweiler, 2017; May, 2017).

On the other end, in a quota system, electricity suppliers are required to purchase certificates from generators up to a certain percentage of their total sales of electricity. Renewable electricity generators sell their electricity in the market, but they receive additional revenues from selling certificates awarded by the regulator. The concept of green certificates comes from the Renewable Portfolio Standard, which is a state-mandated program in the United States that establishes the percentage of the state's overall electricity that must come from renewable energy (Berry and Jaccard, 2001; Kydes, 2007; Barbose et al., 2015; Upton and Snyder, 2017; Young and Bistline, 2018). Similar policies were also implemented in Sweden (Wang, 2006; Jacobsson, 2008; Oikonomou and Mundaca, 2008; Jacobsson et al., 2009; Bergek and Jacobsson, 2010), Belgium (Jacobsson et al., 2009; Verbruggen, 2009), Australia (MacGill, 2010), and Netherlands (Oikonomou and Mundaca, 2008).

As a case of the quota system, the Renewable Obligation (RO) scheme implemented in Great Britain in 2002 was first seen in European countries. ${ }^{3}$ Renewable generators received Renewable Obligation Certificates (ROCs) from the regulator but they do not have priority access to the market and can only export their output if they have a contract with suppliers. The RO scheme was designed to promote the supply of renewable electricity through the market,

\footnotetext{
${ }^{2}$ In the Feed-In Tariffs scheme, owners of an eligible renewable electricity system, such as solar PV, a wind or hydro turbine, or micro CHP, receive payments for every kilowatt-hour they generate. Additional payment is awarded if the owner exports the surplus electricity back to the electricity grid (effectively selling that electricity to the energy supply company). The tariffs will be fixed (adjusted for inflation) for 20 years for almost all of the systems.

${ }^{3}$ The RO scheme was first implemented in England, Wales, and Scotland in 2002/03, and then extended to Northern Ireland from 2005/06.
} 
where both electricity and ROCs are traded between generators and suppliers. Market competition is expected to form the price of ROCs that can affect the transfer payment from suppliers to generators. The RO scheme in the UK was aimed at promoting investment in renewable technology more competitively, rather than providing the investors with a risk-free award or fixed financial support, which is fundamentally different from the FIT system. With the RO scheme, the investors or generators are expected to gain more if their invested renewable projects or technologies can be more cost-efficient. (Morthorst, 2000; Bergek and Jacobsson, 2010; Darmani et al., 2016; Schallenberg-Rodriguez, 2017; Lancker and Quaas, 2019).

The effectiveness of the RO has been assessed by existing literature and its design has been criticised for its lack of effectiveness as a mechanism for encouraging the deployment of renewable projects in its early years (Toke, 2007; Jacobsson et al., 2009; Wood and Dow, 2011; Woodman and Mitchell, 2011). The main problem it created for the development of renewable projects in the UK was the uncertainty associated with the price and the quantity. The price of certificates was not guaranteed, and the support level is not differentiated, meaning that the rate of returns on an investment in a renewable project was not predictable and flat against different renewable technologies at different costs of investment. On one hand, for any renewable project, the uncertainties of investment increase costs in financing new projects due to higher risk and thus discourage investments in renewable technologies; on the other hand, the flat support discouraged investments in more expensive technologies. For example, in 2009, the proportion of electricity generated from wind is only $2.03 \%$, mainly on cheaper onshore projects (DBEIS). However, the introduction of banding and guaranteed headroom in 2009/10 helped intensify incentives for investments in renewable projects. The banding introduced different levels of support for different technologies according to their investment costs and associated risk (DTI, 2007), and the headroom increases the number of certificates imposed on suppliers to purchase. These two amendments unlocked the potential to build large wind farms, expensive offshore projects in particular. ${ }^{4,5}$ In 2018 , the proportion of electricity generated from wind increased to $18.04 \%$ (9.93\% from offshore and $8.11 \%$ from onshore respectively). Meanwhile, the cost of this scheme increased from $£ 228$ million in $2002 / 03$ to $£ 5.3$ billion in $2017 / 18$, which was funded via customers' energy bills, but it remains unknown that how this financial support was distributed among suppliers and generators. After running over 15 years, the Renewables Obligation was closed to new generators in March 2017 and was replaced by Contracts for Difference, in which the government had a better control over the cost of supporting renewable energy, and the generators gained a higher certainty about the price they would receive for their output (Bunn and Yusupov, 2015). ${ }^{6}$

The existing assessment of RO has been mainly based on policy arguments and performance outcomes, few theoretical models have been built up to capture the behaviour of players in the RO scheme with a recycling mechanism. Zhou (2012) constructed a model showing that generators can restrict the sales of the certificates to maximise its profits but without addressing the role of suppliers in affecting sales and price of the certificates. In contrast, our paper makes the first attempt to discuss the interaction between suppliers and

\footnotetext{
${ }^{4}$ Banding allows for various support levels on technologies with different maturity. For example, from 2016/17, onshore wind projects receive $0.9 \mathrm{ROCs} / \mathrm{MWh}$ while offshore wind projects receive $1.8 \mathrm{ROCs} / \mathrm{MWh}$. The highest value was awarded to small wave and tidal stream projects (under $30 \mathrm{MW}$ ) as $5 \mathrm{ROCs} / \mathrm{MWh}$. (Renewables Obligation banding levels: 2013-17, Ofgem).

${ }^{5}$ Guaranteed headroom ensures that the demand for ROC is greater than its supply. For example, for 2018/19, the number of ROC required is 10 percent higher than the number of ROC issued. (Calculating the Level of the Renewables Obligation for 2018/19, Ofgem)

${ }^{6}$ After the closure of RO to new generators in 2017, accredited generators will continue to receive support for the 20 -year period according to their contracts.
} 
generators in trading the certificates, and interaction between suppliers that would be crucial in determining the number and price of ROCs and the size of transfer payment from suppliers to generators. In our theoretical analysis, we find that the introduction of a recycling mechanism in the RO scheme induces strategic behaviour between suppliers, resulting in multiple equilibria that exist upon different prices of ROCs. By taking suppliers' behaviour into account, the generator can choose a specific price of ROCs that produces the maximum transfer payment from the supplier, while induces the supplier to meet its full obligation of ROCs required. However, compared with the scenario without the recycling mechanism, this mechanism produces a lower transfer payment due to the strategic behaviour between suppliers it caused.

Our model further explains that the ROC price and the transfer payment depends also on the relative bargaining powers between suppliers and generators. Both the ROC price and the transfer payment will decline if suppliers have stronger bargaining power in negotiation for the price of ROCs. Furthermore, under the recycling mechanism, the existence of vertical integration encourages competition between generators, leading to a lower price of ROC and transfer payment. Finally, suppliers may collude with each other in choosing their fulfilment of the obligation in purchasing ROCs from generators, but the collusion can be weakened by the vertical integration of a generator with a supplier that pursues different interests from other independent suppliers. The competition between integrated and independent suppliers is conducive to prevent suppliers from jointly abusing the recycling mechanism and minimising the transfer payment.

The paper will be constructed in the following way. Section 2 briefly explains the Renewable Obligation scheme. Section 3 constructs a theoretical model to explore the RO scheme with a recycling mechanism and Section 4 provides further analysis. Section 5 concludes the paper.

\section{The Renewable Obligation in the UK}

The Renewables Obligation (RO) scheme came into effect in 2002 and had been the main support mechanism for large-scale renewable electricity projects in the UK. The Renewable Obligation requires suppliers to supply a certain proportion of their total sales of electricity from renewable sources, by presenting an adequate number of ROCs. Partially, due to the support from the RO scheme, the proportion of electricity generated from renewable sources (hydro, wind, solar, and bioenergy) increased from 3.02\% in 2002 to $33.27 \%$ in 2018 (DBEIS).

At the beginning of each reporting year, the regulator allocates a fixed number of Renewables Obligation Certificates (ROCs) to accredit renewable generators according to their expected electricity output and set up the obligation levels for electricity suppliers. ${ }^{7}$ The required number of ROCs for a particular supplier is the product of its sales of electricity and the obligation level. ${ }^{8}$ During the year, suppliers purchase ROCs from renewable electricity generators, and the price of ROCs is negotiated between them. ROCs can be attached to the electricity sold by renewable generators or can be sold separately.

\footnotetext{
${ }^{7}$ The obligation level set by the government has increased gradually, from 0.03 ROC per MWh in 2002-03 to 0.468 ROC per MWh in 2017-18, for England, Wales, and Scotland.

${ }^{8}$ For example, if a supplier's annual sales of electricity are 1,000 MWh and the obligation level is 0.468 ROC per $\mathrm{MWh}$, then the required number of ROCs is $1,000 \cdot 0.468=468$ for this supplier.
} 
At the end of a reporting year, suppliers use their ROCs to demonstrate that they have fulfilled their obligation. If suppliers fail to present a sufficient number of ROCs, they must pay a penalty, known as the buyout price, for each ROC missed. One feature of the RO scheme implemented in the UK is the recycling mechanism, that is, the penalties from all suppliers are paid into the buyout fund, which is then redistributed back to suppliers in proportion to the number of ROCs they presented, after deducting the System Operator's administration costs. The redistribution payment entitled by each ROC presented is referred to as the recycle value.

\section{A theoretical model}

In this section, we construct a theoretical model to understand the transfer payment from suppliers to generators in the RO scheme with the recycling mechanism. Briefly, our theoretical model is constructed strategically and vertically on the basis of suppliers choosing the quantity of ROCs in response to a given ROC price under the recycling mechanism for maximizing their own gains. Given such Nash-Cournot behaviour of suppliers in choosing ROCs, generators set up a price of ROCs for maximizing their own gains.

\subsection{Suppliers}

Assume that there are a number of electricity suppliers in the market. Consider a supplier $i$ with $q_{i}$ as its annual supply of electricity in MWh (megawatt hour), and $\alpha$ as an obligation level set by the regulator, then the required ROCs for supplier $i$ is $\alpha q_{i}$. Let $R_{i}$ be the number of ROCs presented, then the number of ROCs missed is $\left(\alpha q_{i}-R_{i}\right)$. Let $f$ be the buyout price per ROC missed set by the regulator, then the penalty for the supplier $i$ is $\left(\alpha q_{i}-R_{i}\right) f$, which is paid into the buyout fund.

\subsubsection{The supplier's profit maximisation problem}

The supplier $i$ 's profit function can be written as

$$
\pi_{i}=\left(p^{e}-p^{w}\right) q_{i}-p^{r o c} R_{i}-\left(\alpha q_{i}-R_{i}\right) f+R_{i} E_{i}(r)
$$

where $\left(p^{e}-p^{w}\right) q_{i}$ is the profit from selling electricity to end-users, where $p^{e}$ is the retail electricity price, $p^{w}$ is the wholesale electricity price, $p^{r o c}$ is the price of ROC that suppliers paid to generators, $R_{i}$ is the number of ROCs purchased and presented by supplier $i, p^{r o c} R_{i}$ is the transfer payment from supplier $i$ to generators, $\left(\alpha q_{i}-R_{i}\right) f$ is the penalty payment paid into the buyout fund. For each ROC presented, the supplier receives a recycle value $r$ for it. The recycle value is unknown until the end of the period, i.e., after all suppliers present their ROCs and pay their penalties, so $R_{i} E_{i}(r)$ is the expected redistribution payment based on the expected recycle value $E_{i}(r)$. The profit function can be rewritten as

$$
\pi_{i}=m q_{i}-\left(f+r^{n}\right) R_{i}-\left(\alpha q_{i}-R_{i}\right) f+R_{i} E_{i}(r)
$$

where $m=p^{e}-p^{w}$ denotes the profit margin of electricity sales. The supplier is willing to pay a ROC price that includes two terms, $\left(f+r^{n}\right)$, where $f$ is the penalty (the buyout price) that the supplier needs to pay for every ROC missed, and $r^{n}$ is a premium. This premium may 
reflect the recycle value, $r$, received by the supplier for each ROC presented at the end of the period. In reality, the premium $r^{n}$ is negotiated between suppliers and generators.

As it has been a rising concern on climate change, suppliers with a stronger commitment to green energy are more likely to be welcomed by the public. An assumption we make here is that electricity will be sold by the supplier $i$ in the next period is positively related to the number of ROCs it presents in this period,

$$
s_{i}=\frac{\partial q_{i, t+1}}{\partial R_{i}}>0
$$

where one more unit of ROCs presented in this period leads to $s_{i}$ MWh increase in electricity to be sold by the supplier next period. Here we refer $m s_{i}$ as the future marginal benefits from presenting additional ROCs in the present period, assuming that the retail electricity price and the wholesale electricity price are static over time.

\subsubsection{The determination of the recycle value}

Here we show how the recycle value is determined. The penalty from each supplier is paid into a buyout fund, which is then redistributed to suppliers in proportion to the number of ROCs they presented. The recycle value is the redistribution of penalty payment to each ROC presented by a supplier. By assuming the System Operator's administration cost is zero, the recycle value is equal to the buyout fund divided by total ROCs presented,

$$
r=\frac{(\alpha Q-R) f}{R}=\frac{\sum_{i=1}^{n}\left[\left(\alpha q_{i}-R_{i}\right) f\right]}{\sum_{i=1}^{n} R_{i}} \geq 0
$$

where $n$ is the number of suppliers, $Q$ is the total electricity sold by all suppliers, $Q=\sum_{i=1}^{n} q_{i}$, and $R$ is the total ROCs presented. ${ }^{9}$ As suppliers will not present more ROCs than required, $R \leq \alpha Q$, the recycle value is no less than zero, $r \geq 0$. For simplicity, we consider a case with two suppliers, Supplier 1 and Supplier 2. The recycle value, $r$, becomes

$$
\begin{gathered}
r=\frac{\left(\alpha q_{1}-R_{1}\right) f+\left(\alpha q_{2}-R_{2}\right) f}{R_{1}+R_{2}} \\
r=\frac{\alpha Q f}{R_{1}+R_{2}}-f
\end{gathered}
$$

The first derivative with respect to the number of ROCs presented by Supplier $1, R_{1}$, gives

$$
\frac{\partial r}{\partial R_{1}}=-\frac{\alpha Q f}{\left(R_{1}+R_{2}\right)^{2}}<0 \leftrightarrow R_{1} \uparrow \rightarrow r \downarrow .
$$

Equation (6) suggests that when the number of ROCs presented by Supplier 2, $R_{2}$, remains the same, an increase in the number of ROCs presented by Supplier $1, R_{1}$, reduces the recycle value,

\footnotetext{
${ }^{9}$ By rearranging the equation, the redistribution payment received by a supplier is in proportion to the number of ROCs it presented, $r R_{i}=\frac{R_{i}}{R}(\alpha Q-R) f$. That means, when other things remain the same, a supplier will receive back a higher proportion of the total penalty if it presents more ROCs.
} 
$r$. This is because a higher $R_{1}$ reduces the total penalty (numerator) but increases the total number of ROCs presented (denominator) in Equation (5a). ${ }^{10}$

\subsubsection{Supplier 1's profit maximisation in Choosing ROCs}

After knowing how the recycle value $r$ is determined in Equation (5b), Supplier 1 forms expectation of it in the following way,

$$
E_{1}(r)=\frac{\alpha Q f}{R_{1}+E_{1}\left(R_{2}\right)}-f
$$

Where $E_{1}(r)$ is the recycle value expected by Supplier 1, which depends on Supplier 1's expectation of Supplier 2's presented number of ROCs. After substituting $E_{1}(r)$ in Equation (2), Supplier 1's profit function becomes

$$
\pi_{1}=m Q_{1}-\left(f+r^{n}\right) R_{1}-\left(\alpha q_{1}-R_{1}\right) f+R_{1}\left[\frac{\alpha Q f}{R_{1}+E_{1}\left(R_{2}\right)}-f\right]
$$

By choosing a number of ROCs to maximise profits of Supplier 1, we take the first derivative with respect to the number of ROCs presented by Supplier $1, R_{1}$, is

$$
\frac{\partial \pi_{1}}{\partial R_{1}}=m s_{1}-\left(f+r^{n}\right)+\frac{\alpha Q f E_{1}\left(R_{2}\right)}{\left(R_{1}+E_{1}\left(R_{2}\right)\right)^{2}}
$$

where the first term in Equation (9) is the future marginal benefit, the second term is the marginal cost, and the last term is the marginal benefit from redistribution. When the ROC price is greater than the future marginal benefit,

$$
f+r^{n}>m s_{1}
$$

the turning point can be solved by setting the first derivative (9) equal to zero, gives

$$
R_{1}^{*}=\sqrt{\frac{\alpha Q f E_{1}\left(R_{2}\right)}{f+r^{n}-m s_{1}}}-E_{1}\left(R_{2}\right)
$$

The (11) is the optimal number of ROCs presented by Supplier 1 that maximises its profit. ${ }^{11}$ We refer it to as a response function as it depends on the expectation of Supplier 2's presented number of ROCs. Inequality (10) is the condition that induces strategic behaviour between suppliers. ${ }^{12}$

If Inequality (10) is not met, that is, $f+r^{n} \leq m s_{1}$, suppliers will simply purchase all ROCs required as the marginal cost is less than the future marginal benefit. ${ }^{13}$ From generators' point of view, given that all ROCs allocated or issued by the government are fixed, they have no motivation to agree on a price lower than $m s_{1}$, as no additional ROCs can be sold so a lower price leads to a lower transfer payment from suppliers.

\footnotetext{
${ }^{10}$ The second derivative is greater than zero, $\frac{\partial^{2} r}{\partial\left(R_{1}\right)^{2}}=\frac{2 \alpha Q f}{\left(R_{1}+R_{2}\right)^{3}}>0$, showing that the recycle value is a concave up, decreasing function with $R_{1}$.

${ }^{11}$ The turning point is a maximum as the second derivative is $\frac{\partial^{2}\left(\pi_{1}\right)}{\partial\left(R_{1}\right)^{2}}=-2 \alpha Q E_{1}\left(R_{2}\right) f\left(R_{1}+E_{1}\left(R_{2}\right)\right)^{-3}<0$.

${ }^{12}$ It is also the pre-condition for the square root calculation, $\frac{\alpha Q f E_{1}\left(R_{2}\right)}{f+r^{n}-m \gamma_{1}}>0 \rightarrow f+r^{n}>m \gamma_{1} \rightarrow p^{r o c}>m \gamma_{1}$.

${ }^{13}$ When $m \gamma_{1} \geq f+r^{n}, \frac{\partial \pi_{1}}{\partial R_{1}}>0$, an increase in the presented number of ROCs by Supplier 1 always leads to a higher profit.
} 
The response function in Equation (11) suggests that Supplier 1's profit does not always move towards the same direction with its presented number of ROCs. When $R_{1}$ is lower than the optimal level, a higher $R_{1}$ increases profit; when $R_{1}$ is higher than the optimal level, a higher $R_{1}$ reduces profit,

$$
\begin{aligned}
& R_{1}<R_{1}^{*}=\sqrt{\frac{\alpha Q f E_{1}\left(R_{2}\right)}{f+r^{n}-m s_{1}}}-E_{1}\left(R_{2}\right) \rightarrow \frac{\partial \pi_{1}}{\partial R_{1}}>0 \\
& R_{1}>R_{1}^{*}=\sqrt{\frac{\alpha Q f E_{1}\left(R_{2}\right)}{f+r^{n}-m s_{1}}}-E_{1}\left(R_{2}\right) \rightarrow \frac{\partial \pi_{1}}{\partial R_{1}}<0
\end{aligned}
$$

This suggests that presenting all ROCs required may not be necessarily the optimal strategy, as the optimal number of ROCs that maximises Supplier 1's profit depends on the number of ROCs presented by Supplier 2.

\subsubsection{Supplier 2's profit maximisation in choosing ROCs}

Supplier 2 has a similar profit function with Supplier 1,

$$
\pi_{2}=\left(p^{e}-p^{w}\right) q_{2}-p^{r o c} R_{2}-\left(\alpha q_{2}-R_{2}\right) f+R_{2} E_{2}(r)
$$

in which Supplier 2's expected recycle value depends on its expectation of Supplier 1's presented number of ROCs,

$$
E_{2}(r)=\frac{\alpha Q f}{E_{2}\left(R_{1}\right)+R_{2}}-f
$$

Similarly, by solving the profit maximisation problem, Supplier 2's response function is given as

$$
R_{2}^{*}=\sqrt{\frac{\alpha Q f E_{2}\left(R_{1}\right)}{f+r^{n}-m s_{2}}}-E_{2}\left(R_{1}\right)
$$

which depends on its expectation of Supplier 1's presented number of ROCs.

\subsubsection{A symmetric case under perfect information}

The expected numbers of ROCs presented, $E_{2}\left(R_{1}\right)$ and $E_{1}\left(R_{2}\right)$, are included in these response functions. To solve the equilibrium, we assume that the presented numbers are consistent with expectations,

$$
E_{2}\left(R_{1}\right)=R_{1} \text { and } E_{1}\left(R_{2}\right)=R_{2}
$$

and assume that these two suppliers are identical, so the future marginal benefits are the same,

$$
m s_{1}=m s_{2}=m s
$$

Then the two response functions become

$$
R_{1}=\sqrt{\frac{\alpha Q R_{2} f}{f+r^{n}-m s}}-R_{2} \text { and } R_{2}=\sqrt{\frac{\alpha Q R_{1} f}{f+r^{n}-m s}}-R_{1}
$$


The intersection point of these two response functions solves the equilibrium values of $R_{1}$ and $R_{2}$. At the equilibrium, the number of ROC presented by Supplier 1 and Supplier 2 is

$$
R_{1}^{e}=R_{2}^{e}=\frac{\alpha Q f}{4\left(f+r^{n}-m s\right)}
$$

and the total number of ROC presented is

$$
R^{e}=R_{1}^{e}+R_{2}^{e}=\frac{\alpha Q f}{2\left(f+r^{n}-m s\right)}
$$

At the equilibrium, the presented number of ROCs depends on the obligation level $\alpha$, the total electricity sold by two suppliers $Q$, the future marginal benefit $m s$, the buyout price $f$, and the premium $r^{n}$. In our following analysis, we assume that only varying variable is the premium $r^{n}$, which is negotiated between generators and suppliers. Equation (20) suggests that there are multiple equilibria for different values of premium $r^{n}$. In particular, the derivative of Equation (20) is

$$
\frac{\partial R^{e}}{\partial r^{n}}<0 \text { when } R^{e}<\bar{R}
$$

where $\bar{R}$ is the number of ROCs issued or allocated by the government. The (21) or (20) suggests that a higher (lower) premium reduces (increases) the number of ROCs presented at the equilibrium and so the percentage of obligation met by suppliers. ${ }^{14}$ As the number of ROC presented is constrained by $\bar{R}$, the first derivative (21) does not hold anymore when $R^{e}=\bar{R}$. The relation between the obligation fulfilment and the ROC price is summarised in Figure 1.

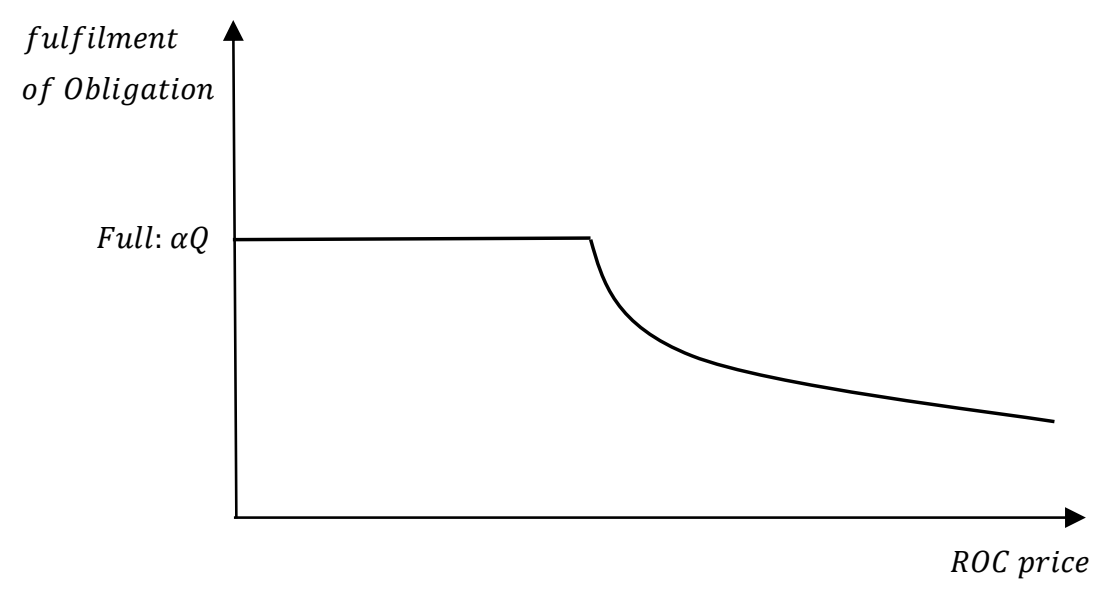

Figure 1: The obligation met by suppliers. Figure 1 shows the obligation met by suppliers given the ROC price. The concave up, decreasing curve is determined by the signs of the first derivative and second derivative of Equation (20).

\footnotetext{
${ }^{14}$ The second derivative is $\frac{\partial^{2}\left(R^{e}\right)}{\partial\left(r^{n}\right)^{2}}=\alpha Q f\left(f+r^{n}-m \gamma\right)^{-3}>0$, suggesting that $R^{e}$ is a concave up, decreasing function with $r^{n}$.
} 


\subsection{The generator}

In reality, the premium (and then the ROC price) is negotiated between suppliers and generators. As the RO scheme is designed to help renewable generators receive an additional transfer payment from suppliers, we first assume that a single renewable generator sets up a price in the ROC market to explore the best possible outcome for itself. Previous analysis shows that the number of ROCs presented by suppliers depends on the premium (and then the ROC price), the question now becomes how the ROC price is set by the generator.

Consider that this renewable electricity generator has an estimated annual maximum output $Q^{c} \mathrm{MWh}$, calculated from its capacity and the load factor. In the Renewable Obligation scheme, after becoming an accredited station, the regulator allocates $\bar{R}=\beta Q^{c}$ for ROCs to this generator. The support level $\beta$ indicates the number of ROCs allocated to each MWh it generates. This parameter remained at one, $\beta=1$, from 2002-03 to 2008-09 for all types of technology. After the introduction of banding, it varies for technologies depending upon their relative maturity, development cost and associated risk (DTI, 2007).

\subsubsection{The generator's profit maximisation problem}

The generator's profits include two components, i.e., the profit from selling electricity, $\Pi^{s}$, and the transfer payment from selling ROCs, $\Pi^{r o c}$. The wholesale electricity price $p^{w}$ is assumed as given to be the same for both the renewable generator and traditional generators in the competitive electricity wholesale market. Let $Q^{g}$ be the actual quantity of electricity the renewable generator sold and $R$ be the quantity of ROC sold. The generator's profits become

$$
\Pi=\Pi^{s}+\Pi^{r o c}=\left(p^{w}-c\right) Q^{g}+p^{r o c} R=\left(p^{w}-c\right) Q^{g}+\left(f+r^{n}\right) R
$$

subject to the constraint of availability of ROCs,

$$
R \leq \bar{R}=\beta Q^{c}
$$

where $c$ is the constant marginal cost of producing green electricity, $\beta Q^{c}$ is the number of ROCs allocated to the generator. We assume that the number of ROCs allocated is equal to the number of ROCs required, $\bar{R}=\alpha Q$. This assumption helps focus on the strategic behaviour between suppliers in our model. When the allocated number is greater than the required number, $\bar{R}>\alpha Q$, after suppliers have fully fulfilled their obligation, $\alpha Q$, and there is no demand for the rest of ROCs, $\bar{R}-\alpha Q$, leading to a sudden collapse of ROCs price. In the UK, the introduction of the guaranteed headroom in 2009-10 removed this possibility and helped reduce the uncertainty associated with the price. ${ }^{15}$

Assume that the generator knows the strategic behaviour between suppliers in choosing ROCs and understand that the quantity of ROCs demanded depends on the premium, and sales of renewable electricity are linked to sales of ROCs after taking Equation (20) into account, the generator will maximise profits below,

$$
\Pi=\left(p^{w}-c\right) Q^{g}\left(R\left(r^{n}\right)\right)+\left(f+r^{n}\right) \frac{\alpha Q f}{2\left(f+r^{n}-m s\right)}
$$

\footnotetext{
${ }^{15}$ A more complicated case arises when the allocated number is less than the required number, $\bar{R}<\alpha Q$. In this case, the recycling mechanism is also responsible for refunding the unjustified penalty. Nonetheless, the problem of strategic behaviour that leads to a lower transfer payment discussed in the paper remains.
} 
by taking the first derivative with respect to the premium $r^{n}$ which gives,

$$
\frac{\partial \Pi}{\partial r^{n}}=\left(p^{w}-c\right) \frac{\partial Q^{g}}{\partial R} \frac{\partial R}{\partial r^{n}}-m s \frac{\alpha Q f}{2}\left(f+r^{n}-m s\right)^{-2}<0 \text { when } R<\bar{R}
$$

The first term is the product of the positive marginal impact of the number of ROCs sold on the sales of renewable electricity, $\partial Q^{g} / \partial R>0$, and the negative marginal impact of the premium on the number of ROCs sold, $\partial R / \partial r^{n}<0 .{ }^{16}$ The second term is the negative marginal impact of the premium on the transfer payment. As both terms are negative, this first derivative shown in (25) is less than zero, suggesting that a lower premium $r^{n}$ leads to a higher profit to the generator from selling electricity and ROCs.

\subsection{The ROC price, compliance, and the transfer payment}

\subsubsection{The transfer payment and the premium}

In this section, we explore the relationship between the ROC price and the transfer payment from suppliers to the generator. In the first phase, before all of the allocated ROCs are sold, the number of ROCs sold depends on the premium. Taking Equation (20) into account, the transfer payment to the generator from selling ROCs is

$$
\Pi^{r o c}=p^{r o c} R=\left(f+r^{n}\right) \frac{\alpha Q f}{2\left(f+r^{n}-m s\right)} \text { when } R<\bar{R}
$$

The first derivate with respect to the premium, $r^{n}$, is

$$
\frac{\partial \Pi^{r o c}}{\partial r^{n}}=-\frac{m \gamma \alpha Q f}{2\left(f+r^{n}-m s\right)^{2}}<0 \text { when } R<\bar{R}
$$

where (27) suggests that a lower premium will lead to a higher transfer payment from suppliers to the generator. ${ }^{17}$ However, as the number of ROCs allocated is fixed for suppliers to purchase, when all of the allocated ROCs are sold, the transfer payment becomes

$$
\Pi^{\text {roc }}=p^{\text {roc }} \bar{R}=\left(f+r^{n}\right) \bar{R} \text { when } R=\bar{R}
$$

and its first derivative is

$$
\frac{\partial \Pi^{r o c}}{\partial r^{n}}=\bar{R}>0 \text { when } R=\bar{R}
$$

which suggests that a decline in the premium will decrease the transfer payment to the generator. The relation between the transfer payment and the ROC price can be summarised in Figure 2 .

\footnotetext{
${ }^{16}$ Due to the competitiveness in the electricity wholesale market, we assume that the sale of electricity by the renewable generator positively depends on the number of ROCs it sells, $\partial Q^{g} / \partial R>0$. This assumption implies that the generator sells more electricity when more ROC is sold. In reality, the renewable generator can sell its electricity and ROCs separately. In this case, we may have $\partial Q^{g} / \partial R=0$, but our conclusion is not affected, as the first derivative (25) is still negative.

${ }^{17}$ The second derivative is greater than zero, $\frac{\partial^{2} \Pi^{r o c}}{\partial\left(r^{n}\right)^{2}}=\frac{m \gamma \alpha Q f}{\left(f+r^{n}-m \gamma\right)^{3}}>0$, suggesting that the function of transfer payment is concave-up, decreasing with $r^{n}$, as shown in Figure 2.
} 


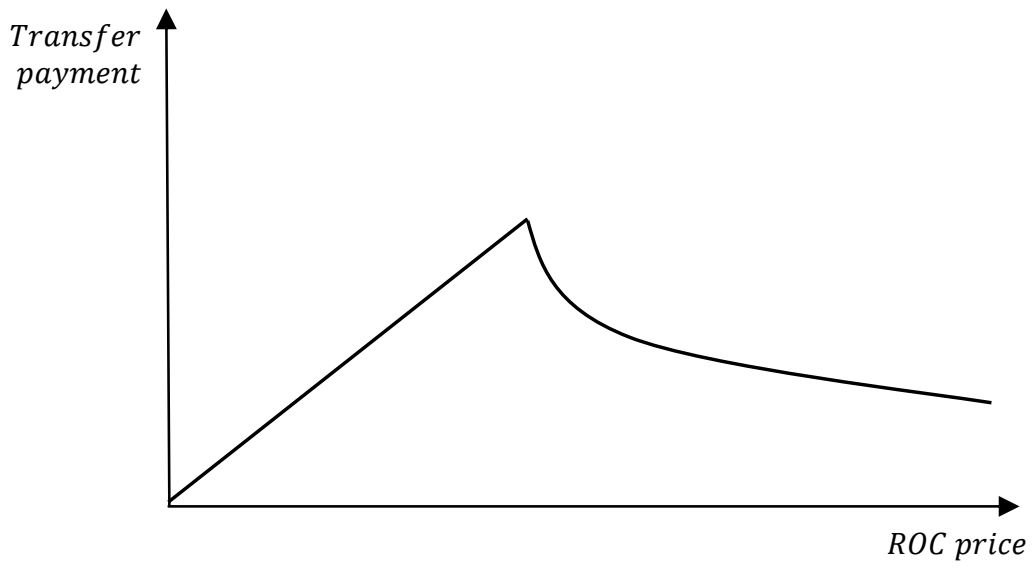

Figure 2: The transfer payment from suppliers to the generator via selling ROCs. Figure 2 shows the transfer payment from suppliers to the generator affected by ROC prices. The straight line is determined by the linear relation between the transfer payment and the ROC price after all ROC is sold. The concave up, decreasing curve is determined by the signs of the first derivative and second derivative of Equation (26).

\subsubsection{The maximum transfer payment}

We have shown that the fulfilment of the obligation increases when the premium (or the ROC price) declines until the obligation is fully met. Therefore, we first find the ROC price that can affect the delivery of the full obligation fulfilment. In this case, the total presented number of ROCs is equal to the total required number of ROCs, $\alpha Q$, and it is shared equally by those two identical suppliers,

$$
R^{e}=\alpha Q \leftrightarrow R_{1}^{e}=R_{2}^{e}=\frac{\alpha Q}{2}
$$

Substitute (30) into Equation (19) gives,

$$
\frac{\alpha Q f}{4\left(f+r^{n}-m s\right)}=\frac{\alpha Q}{2}
$$

Then the ROC price is solved as

$$
\left(f+r^{n}\right)=m s+\frac{f}{2} \leftrightarrow p^{r o c}=m s+\frac{f}{2}
$$

Equation (32) suggests that the obligation is fully met when the ROC price is $(m s+f / 2)$, as shown in Figure 3. On the one hand, any lower ROC price does not increase the number of ROCs presented as all ROCs have been sold. On the other hand, any higher ROC price reduces both the number of ROCs sold and the percentage of obligation met by suppliers according to the first derivative (21). 


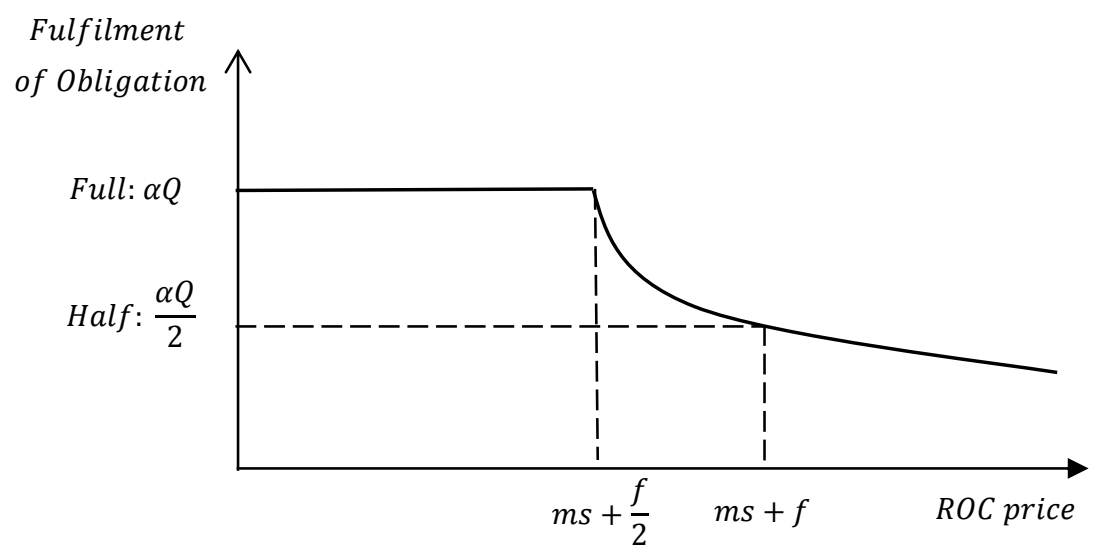

Figure 3: The obligation met by suppliers. Figure 3 shows the obligation met by suppliers given the ROC price. The obligation is fully met when the ROC price is $(m s+f / 2)$ or less. Any higher ROC price will reduce the number of ROC presented. For example, when the ROC price is $(m s+f)$, the obligation is half met.

The transfer payment from suppliers to the generator at the ROC price of (32) is,

$$
\Pi^{r o c}=p^{r o c} R=\left(m s+\frac{f}{2}\right) \alpha Q
$$

which is the maximum transfer payment from the supplier to the generator in the RO scheme with the recycling mechanism, shown as point A in Figure 4. On the one hand, the generator has no motivation to set a lower ROC price to receive a lower transfer payment as no additional ROCs can be sold. On the other hand, as suggested by the first derivative (27), any higher ROC price reduces the number of ROC sold and leads to a lower transfer payment. In Section 4.1, we will compare this transfer payment with that from a scenario without the recycling mechanism.

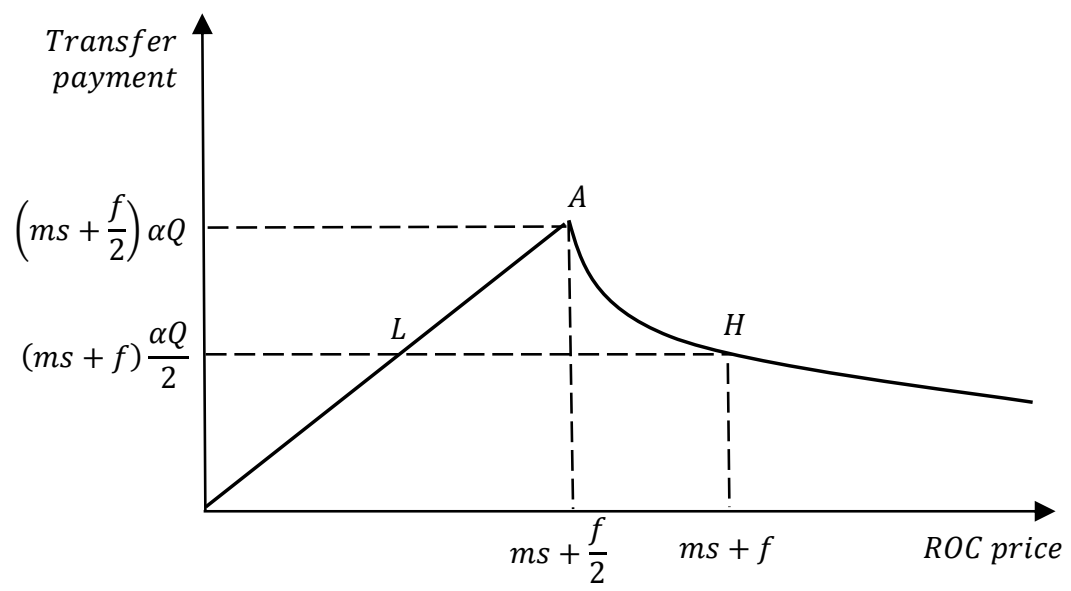

Figure 4: The transfer payment from suppliers to the generator via selling ROCs. Figure 4 shows the transfer payment from suppliers to the generator given the ROC price. The transfer payment is maximised when the ROC price is at $(m s+f / 2)$ and the obligation is fully met. Any lower ROC price leads to a lower transfer payment as no more ROCs can be sold. Any higher ROC price leads to a lower transfer payment as suppliers present less ROCs. For example, the transfer payment is $(m s+f) \alpha Q / 2$ when the ROC price is $(m s+f)$. 
Here we illustrate an example of a higher ROC price. Consider the generator sets a higher ROC price at $(m s+f)$, then, according to Equation (20), the total presented number of ROCs is

$$
R^{e}=\frac{\alpha Q f}{2(m s+f-m s)}=\frac{\alpha Q}{2} \leftrightarrow R_{1}^{e}=R_{2}^{e}=\frac{\alpha Q}{4}
$$

which shows that half of the required number of ROCs, $\alpha Q / 2$, is shared by those two identical suppliers. Therefore, the obligation is half met when the ROC price is $(m s+f)$, greater than the price for the full obligation fulfilment. The transfer payment in this case is

$$
\Pi^{r o c}=p^{r o c} R=(m s+f) \frac{\alpha Q}{2}
$$

which is less than the transfer payment under the full obligation fulfilment, and it is shown at point $\mathrm{H}$ in Figure 4. At this point, the generator is willing to start to consider reducing the premium (and thus the ROC price) to sell more ROCs until all required ROCs are sold, moving back towards point $\mathrm{A}$.

Another point shown in Figure 4 is that the transfer payment at point $\mathrm{H}$ is $(m s+f) \alpha Q / 2$, but there is another point $\mathrm{L}$ also produces the same amount of transfer payment, indicating suppliers to choose different fulfilments of obligation in response to different prices of ROCs. At point $\mathrm{L}$, the ROC price is lower than $(m s+f) / 2$, and then all required number of ROCs are sold, contrasting to only half of the obligation met at point $\mathrm{H}$. Therefore, we suggest that both the generator and suppliers should prefer point $\mathrm{L}$, instead of point $\mathrm{H}$, as the generator benefits from higher sales of electricity which may be related to the number of ROC sold and suppliers could brand themselves as of green suppliers by meeting their targets.

\section{Discussion}

\subsection{A model without the recycling mechanism}

In previous sections, we have shown the transfer payment when there is a recycling mechanism. In this section, we discuss the suppliers' behaviour when there is no recycling mechanism and then compare the results of these two scenarios.

In the scenario without the recycling mechanism, where removes the term of redistribution payment from Equation (2), but still hold penalty $f$ imposed on each ROC missed by suppliers, then the supplier's profit function becomes,

$$
\pi_{i}^{\prime}=m q_{i}-\left(f+r^{n}\right) R_{i}-\left(\alpha q_{i}-R_{i}\right) f
$$

The first derivative with respect to $R_{i}$ gives,

$$
\frac{\partial \pi_{i}^{\prime}}{\partial R_{i}}=m s_{i}-r^{n}
$$

which implies that

$$
\begin{gathered}
r^{n}>m s_{i} \text { or } p^{r o c}>m s_{i}+f \leftrightarrow R_{1}=0 \\
r^{n}=m s_{i} \text { or } p^{r o c}=m s_{i}+f \leftrightarrow R_{1}=\text { random number } \\
r^{n}<m s_{i} \text { or } p^{r o c}<m s_{i}+f \leftrightarrow R_{1}=\text { required number }
\end{gathered}
$$


That is, suppliers will not purchase any ROCs if the premium is greater than the future benefit, but purchase all ROC required when the premium is less than the future benefit. Therefore, the generator will choose a ROC price that is marginally lower than the sum of the future benefit and the buyout price to encourage suppliers to purchase all ROC required, thus the transfer payment from suppliers to the generator is

$$
\left(\Pi^{r o c}\right)^{\prime} \approx(m s+f) \alpha Q
$$

where $m s$ denotes the future marginal benefits. The (39) implies that the transfer payment without the recycling mechanism is higher than the maximum transfer payment under the recycling mechanism, $(m s+f / 2) \alpha Q$, shown in the (33). This is because of the ROC price, $(m s+f)$, can lead to the full obligation fulfilment without the recycling mechanism in this scenario but only a half fulfilment of the obligation met in the scenario with the recycling mechanism due to the strategic behaviour between suppliers, as shown in Figure 4 and Equation (35). Therefore, the recycling mechanism may be introduced to incentivise suppliers to meet their obligation, but it unintentionally leads to a lower transfer payments from suppliers to generators. ${ }^{18}$

\subsection{The transfer payment under different bargaining powers}

So far, we assume that the generator has a price-setting power to sell ROCs at a price of $(m s+f / 2)$ for achieving the maximum transfer payment of $(m s+f / 2) \alpha Q$ from suppliers to itself. In reality, the premium (or the ROC price) is negotiated between suppliers and generators, and the final outcome depends on their bargaining powers. From the discussion on Equation (10), the generator will not agree on any price lower than $m s$, as all suppliers will purchase and present all ROC required at this ROC price. From the discussion on Equation (32), the generator will not set any ROC price higher than $(m s+f / 2)$, as a higher price reduces the number of ROCs bought and so leads to a lower transfer payment. Therefore, the ROC price is in a range from $m s$ to $(m s+f / 2)$, and obligation is always fully met, as shown in Figure 5 . As a result, the transfer payment has a range from $m s \alpha Q$ to $(m s+f / 2) \alpha Q$, as shown in Figure 6.

\footnotetext{
${ }^{18}$ According to the regulator's report, the total cost to support the RO scheme is approximated as $(f+r) \alpha Q$. A survey study would help examine how this financial support is distributed between generators and suppliers.
} 


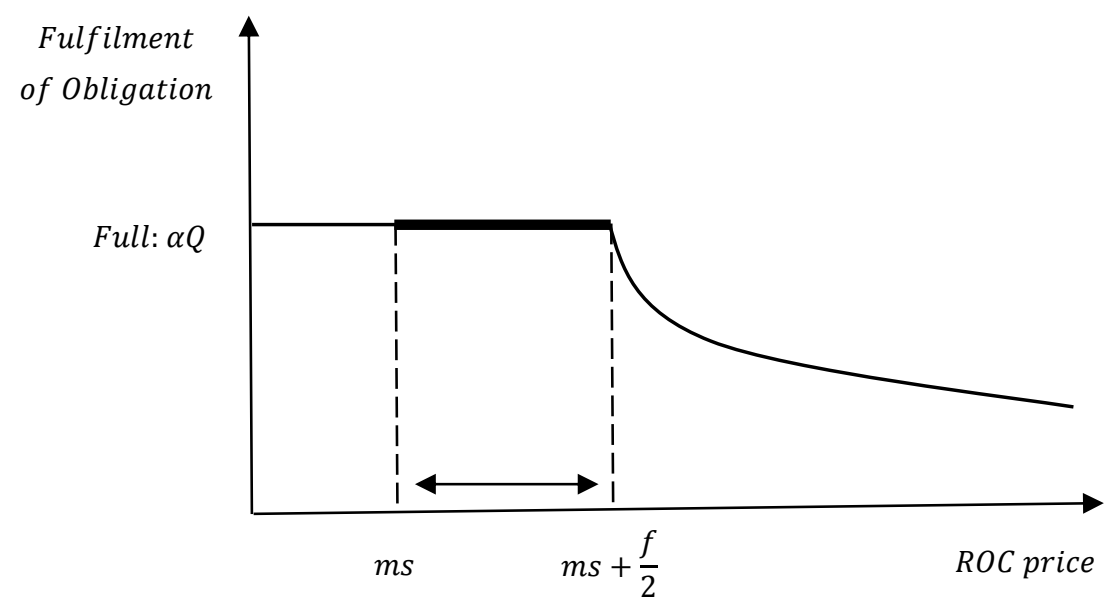

Figure 5: The obligation met by suppliers. Figure 5 shows the obligation met by suppliers given the ROC price. The final outcome depends on the bargaining powers between the generator and suppliers. As shown by the bolded line, the ROC price has a range from $m s$ to $(m s+f / 2)$, while the obligation is always fully met.

Figure 6: The transfer payment from suppliers to the generator via selling ROCs

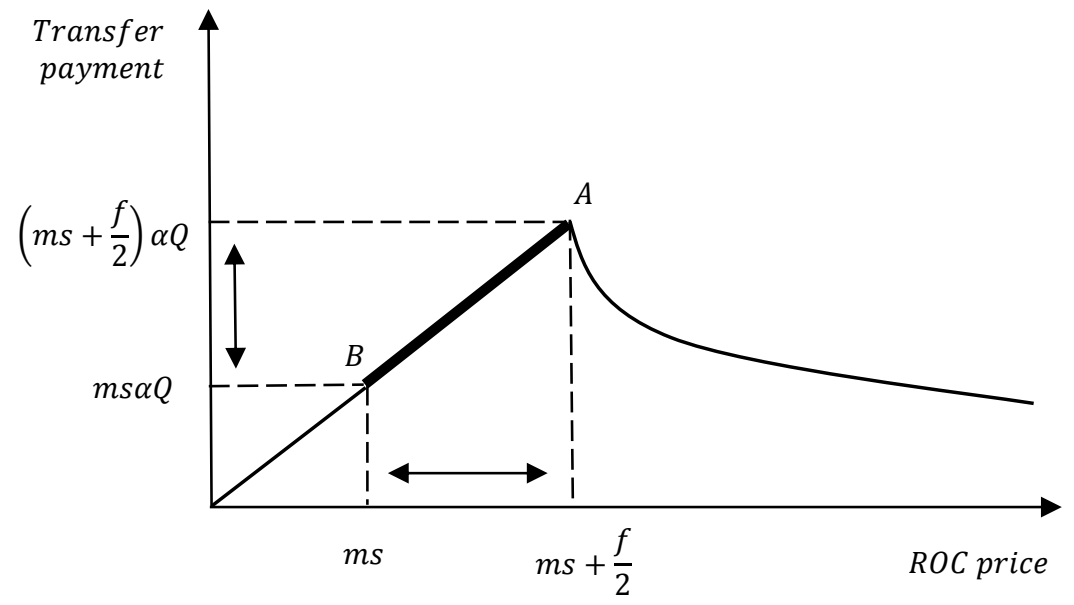

Figure 6: The transfer payment from suppliers to the generator via selling ROCs. Figure 6 shows the transfer payment from suppliers to the generator given the ROC price. The final outcome depends on the bargaining powers between the generator and suppliers. As shown by the bolded line, the ROC price has a range from $m$ s to $(m s+f / 2)$ and the transfer payment has a range from $m s \alpha Q$ to $(m s+f / 2) \alpha Q$, while the obligation is always fully met.

When the generator is dominant in bargaining, the equilibrium is achieved at point $\mathrm{A}$, at which the maximum transfer payment is achieved. In contrast, when suppliers are dominant in bargaining, the equilibrium is reached at point $\mathrm{B}$, at which the minimum transfer payment is delivered. The generator's bargaining power shall be high if there is only one generator on the market. If there is more than one generator on the market, we argue that the ROC trading market is still in favour of the generators to bargain or negotiate with suppliers. This is because, first, the headroom mechanism creates a stronger favour for generators to bargain as the mechanism introduces more demand than supply in trading ROCs. Secondly, the recent change in public attitude towards climate change and green energy puts high pressure on suppliers to become 
more environmental-friendly, raising further demand for ROCs. Thirdly, the gradual decline in the cost of renewable energy reduces the generator's dependence on the transfer payment, which previously was crucial for the generator's economic viability. Fourthly, the increasing competition in the electricity retail sector reduces the probability of cooperation between suppliers aiming to negotiate for a lower ROC price.

\subsection{The strategic competition under the recycling mechanism and vertical integration}

The Big Six energy firms are all vertically integrated as they have both electricity generation and electricity retailing activities. Together, they generate about $70 \%$ of total electricity generation in Great Britain (CMA, 2016). ${ }^{19}$ The data about the proportion of renewable generation owned by vertically integrated firms is not available but we can generalise the current vertical market structure of UK electricity industry into two cases: the first is one generator to two suppliers, where one supplier is vertically integrated to the generator and another one is independent. The second case is two generators to two suppliers, where one generator and one supplier is vertically integrated as one firm against another independent generator and independent supplier. These two cases are shown in Figures 7 and 8.

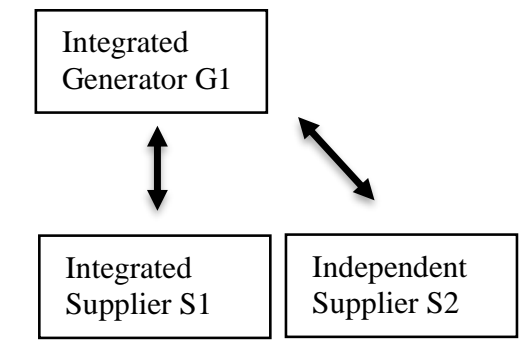

Figure 7: Case One: One Generator to Two Suppliers

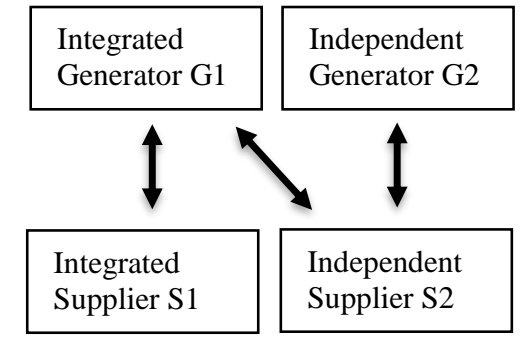

Figure 8: Case Two: Two Generators to Two Suppliers

In Case One, assume generator G1 has two strategies in pricing ROCs for supplier S1 and S2: charge the higher price at point $\mathrm{A}$ for a higher transfer payment or charge the lower price at point $B$ for a lower transfer payment in Figure 6. Apparently, charging the higher price is preferred by G1 because the transfer payment from integrated supplier S1 to G1 will not affect the profits of the integrated firm as a whole, but the transfer payment from independent supplier S2 to generator G1 affects the revenues of the integrated firm.

In Case Two, when two generators are symmetric in terms of capacity and ROCs allocated, together with symmetric suppliers S1 (integrated) and S2 (independent) demand for ROCs, our analysis shows that the vertical integration between G1 and S1 promotes the upstream competition between G1 and G2, leading to a low price of ROCs and a lower transfer payment, as shown at point B in Figure 6. Here we use a numerical example to justify the claim above. By assuming that the number of ROCs allocated to each generator is 100 , we start from an equilibrium that both integrated generator G1 and independent generator G2 charge a high

\footnotetext{
${ }^{19}$ The Big Six are British Gas, EDF, E.ON, Npower, Scottish Power, and SSE.
} 
price of ROC, as shown at point A in Figure 6. By further assuming a penalty rate of $£ 20$ on each ROC missed, and a high price at $£ 10$ per ROC, G1 can receive $£ 1,000$ from its own supplier S1 (for 100 ROCs at the price of £10) as the internal transfer payment. ${ }^{20}$ At the high price, the independent generator G2 receives $£ 1,000$ (for 100 ROCs at the price of £10) from the independent supplier S2. This equilibrium is referred to as the H-H equilibrium in Table 1.

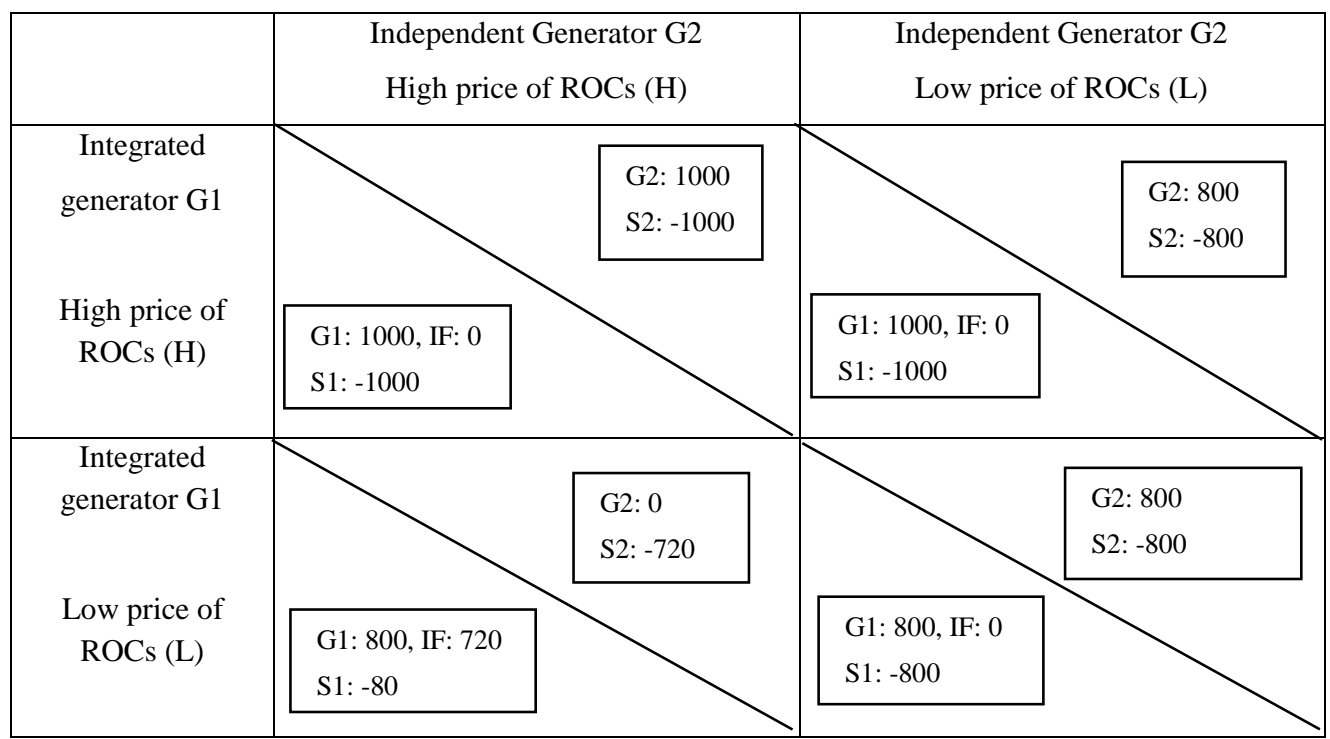

Table 1: Equilibria in Case Two. G presents generator, S presents supplier, IF presents the vertical integration.

To seek more gains from trading ROCs, G1 has an incentive to deviate from this $\mathrm{H}-\mathrm{H}$ equilibrium. Suppose, G1 cuts the price of ROCs from $£ 10$ to $£ 8$, and G2 still charges a higher price at $£ 10$. In response to the lower price charged by G1, S2 intends to switch from G2 to G1. G1 can take the intention of S2 as an advantage to design a mixed strategy to seek more gains for the integrated firm. For example, G1 can offer 60 ROCs to S1 and 40 ROCs to S2, conditional on that S2 does not purchase any ROCs from G2. For S2, it pays $£ 720$ if it accepts the offer, as it makes a transfer payment of $£ 320$ to $\mathrm{G} 1$ (for $40 \mathrm{ROC}$ at the price of $£ 8$ ), pays a penalty of $£ 1,200$ (for 60 missing ROCs at the buyout price of $£ 20$ ) and receives a recycle payment of $£ 800$ ( $40 \%$ of total penalty of $£ 2,000$ ). Otherwise, it still pays $£ 1000$ to G2 who charges each ROC at $£ 10$, so the offer is credible for S2 to accept. Meanwhile, G1 receives a total of $£ 800$ from selling ROCs, including the internal transfer payment of $£ 480$ from S1 (for 60 ROCs at the price of $£ 8$ ) and the external transfer payment of $£ 320$ from S2. In addition, the loss to $S 1$ is $-£ 80$, as it makes an internal transfer of $£ 480$ to G1, pays a penalty of $£ 800$ (for 40 missing ROCs at the buyout price of $£ 20$ ) and receives a recycle payment of $£ 1,200$ (60\% of total penalty of $£ 2000$ ). Therefore, as an integrated firm (IF), if it reduces the ROC price from $£ 10$ to $£ 8$, it receives a total net gain of $£ 720$, which comes from $£ 800$ received by G1 selling ROCs less the loss of $£ 80$ by S 1 for purchase of ROCs. Apparently, $£ 720$ as the net gain of the integrated firm in the $\mathrm{L}-\mathrm{H}$ is higher than the $\mathrm{H}-\mathrm{H}$ case of $£ 0$, so $\mathrm{G} 1$ has the incentive to reduce the price of ROC.

When the equilibrium moves from $\mathrm{H}-\mathrm{H}$ to $\mathrm{L}-\mathrm{H}$, the transfer payment received by $\mathrm{G} 2$ reduced from $£ 1,000$ to $£ 0$. To regain the transfer payment from $S 2, \mathrm{G} 2$ needs to compete with

\footnotetext{
${ }^{20}$ If assume the future marginal benefit is zero, our model in section 3 suggests that the ROC price is the half of the penalty.
} 
G1 in lowering the ROC prices to $£ 8$, leading a new strategic equilibrium of the low price versus the low price, i.e., the L-L equilibrium in Table 1. At this equilibrium, G1 receives $£ 800$ from its own supplier S1 as the internal transfer of payment and the independent generator G2 receives $£ 800$ from the independent supplier S2. This L-L equilibrium can be seen as point B in Figure 6. Therefore, the existence of vertical integration drives down the ROC price by encouraging upstream competition, leading to a lower transfer payments from suppliers. The process of moving from the $\mathrm{H}-\mathrm{H}$ equilibrium to the $\mathrm{L}-\mathrm{L}$ equilibrium can be presented as a movement from point A to point B in Figure $6 .^{21}$

However, point $\mathrm{B}$ may not be achieved when there is no integration between a generator and a supplier. Case Three with two independent generators and two independent suppliers is shown in Figure 9. In this case, independent suppliers can collude with each other in pursuing their common interest of minimising the transfer payment to generators. For example, of 100 ROCs required for obligation, each supplier can present one ROC and pay a penalty for 99 ROCs missed. Under the recycling mechanism, the equal share of the purchased ROCs can cancel out the penalty payment of each other. This extreme collusion strategy abuses the recycling mechanism to produce the worst case of almost zero transfer payment from suppliers to generators. Although our analysis of the Nash-Cournot strategy suggests that suppliers have the motivation to deviate from this arrangement for higher payoff in the short run, the benefits from collusion in repeated periods may overweight.

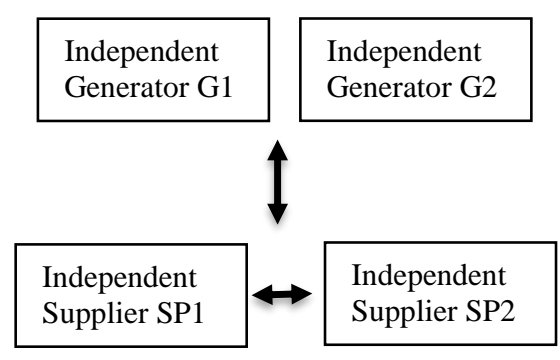

Figure 9: Case Three: Two Generators to Two Suppliers without integration

The first remedy to the worst case of nearly zero transfer payment is the increasing competition in the electricity retail market. In the UK market, other than the six integrated large suppliers, there is an increasing number of independent suppliers, competing with each other in the ROC trading market. With a large number of independent suppliers, it becomes more difficult to prevent the deviation from the collusion strategy, which turns the Nash-Cournot strategy more favourable for suppliers to consider.

Second, although the existence of vertical integration encourages upstream competition and reduces the transfer payment, it could prevent the worst case of nearly zero transfer payment. If there is an integrated firm as in Case Two, integrated supplier S1 and independent supplier S2 have different interests. The former takes the interest of the integrated firm into account by supporting the generator via the internal transfer payment, while the latter seeks to maximise its own profits. The different interests make two suppliers unlikely to collude with each other in setting up a joint strategy to abuse the recycling mechanism. Therefore, the integrated firm can prevent the worst case of nearly zero transfer payment.

\footnotetext{
${ }^{21}$ Regarding the H-L equilibrium, G1 places its own S1 in a cost disadvantage for pricing electricity at the endusers market when compared with independent S2 that has a lower cost of ROCs than S1. As a result, G1 will switch from $\mathrm{H}$ to $\mathrm{L}$ in order to have $\mathrm{S} 1$ be competitive as same as $\mathrm{S} 2$ for the end-user electricity market.
} 


\section{Conclusions}

In this paper, we have constructed a theoretical model to show that the recycling mechanism in the Renewable Obligation scheme induces strategic behaviour between suppliers. Among multiple equilibria upon different ROC prices, the renewable generator would prefer a specific price to receive the maximum transfer payment and encourage suppliers to meet their obligation in full. Then we show that this maximum is lower than that in the scenario without the recycling mechanism, because the strategic behaviour induced reduces the transfer payment from suppliers to generators, weakening the aim of the Renewable Obligation scheme. Also, whether the maximum transfer payment can be achieved depends on the relative bargaining power between generators and suppliers. Our discussion on the behaviour of the vertically integrated firm supports the claim that the lower ROC price and transfer payment will be chosen under the recycling mechanism due to upstream competition between generators. But the existence of vertical integration prevents the collusion of suppliers in jointly abusing the recycling mechanism for choosing the least fulfilment of the obligation and the lowest transfer payment.

In future research, we would like to follow up on a survey to find out how the practice aligns with the model. The information on the ROC price received by generators would help understand the distribution of financial support between suppliers and generators. Also, a survey from suppliers would help understand whether they have taken their competitors' position into account when they decide the level of fulfilment. Furthermore, we would like to follow up on a cross-country study to have a better understanding of the impact of the recycling mechanism, which seems a unique design in the UK, while the quota system is also employed in other countries, such as United States, Australia, and Sweden.

Our study has several limitations. First, there are only two identical suppliers in our theoretical model. A more complicated model involving multiple suppliers with different sizes would give additional conclusions. Secondly, the equilibrium solved by our model is based on the assumption of perfect information between suppliers in a static setting. As in reality, it is unlikely to know the competitor's decision until the end of the reporting year, adding dynamic interactions and learning could bring interesting findings. Thirdly, it is not clear whether our arguments about vertical integration can still hold when the competition between vertically integrated firms is discussed. Therefore, if we can address these limits for our future research, it will be more insightful for understanding the market of the UK renewable electricity trade and the role of supporting policies.

\section{Acknowledgement}

Thanks for the comments from two anonymous referees. 


\section{Reference}

Antweiler, W. (2017). A two-part feed-in-tariff for intermittent electricity generation. Energy Economics, 65, 458-470. doi:10.1016/j.eneco.2017.05.010

Barbose, G., Bird, L., Heeter, J., Flores-Espino, F., and Wiser, R. (2015). Costs and benefits of renewables portfolio standards in the United States. Renewable and Sustainable Energy Reviews, 52, 523-533. doi:10.1016/j.rser.2015.07.175

Bergek, A., and Jacobsson, S. (2010). Are tradable green certificates a cost-efficient policy driving technical change or a rent-generating machine? Lessons from Sweden 20032008. Energy Policy, 38(3), 1255-1271. doi:10.1016/j.enpol.2009.11.001

Berry, T., and Jaccard, M. (2001). The renewable portfolio standard: design considerations and an implementation survey. Energy Policy, 29(4), 263-277. doi:10.1016/S03014215(00)00126-9

Bunn, D., and Yusupov, T. (2015). The progressive inefficiency of replacing renewable obligation certificates with contracts-for-differences in the UK electricity market. Energy Policy, 82, 298-309. doi:10.1016/j.enpol.2015.01.002

Butler, L., and Neuhoff, K. (2008). Comparison of feed-in tariff, quota and auction mechanisms to support wind power development. Renewable Energy, 33(8), 1854-1867. doi:10.1016/j.renene.2007.10.008

CMA. (2016). Energy Market Investigation (www.gov.uk).

Couture, T., and Gagnon, Y. (2010). An analysis of feed-in tariff remuneration models: Implications for renewable energy investment. Energy Policy, 38(2), 955-965. doi:10.1016/j.enpol.2009.10.047

Darmani, A., Rickne, A., Hidalgo, A., and Arvidsson, N. (2016). When outcomes are the reflection of the analysis criteria: A review of the tradable green certificate assessments. Renewable and Sustainable Energy Reviews, 62, 372-381. doi:10.1016/j.rser.2016.04.037

DBEIS. Energy Trend, various years (www.gov.uk).

del Río González, P. (2008). Ten years of renewable electricity policies in Spain: An analysis of successive feed-in tariff reforms. Energy Policy, 36(8), 2917-2929. doi:10.1016/j.enpol.2008.03.025

del Río, P., and Gual, M. A. (2007). An integrated assessment of the feed-in tariff system in Spain. Energy Policy, 35(2), 994-1012. doi:10.1016/j.enpol.2006.01.014

DTI. (2007). Reform of the Renewables Obligation (webarchive.nationalarchives.gov.uk).

Fouquet, D., and Johansson, T. B. (2008). European renewable energy policy at crossroadsFocus on electricity support mechanisms. Energy Policy, 36(11), 4079-4092. doi:10.1016/j.enpol.2008.06.023

Haas, R., Panzer, C., Resch, G., Ragwitz, M., Reece, G., and Held, A. (2011). A historical review of promotion strategies for electricity from renewable energy sources in EU countries. Renewable and Sustainable Energy Reviews, 15(2), 1003-1034. doi:10.1016/j.rser.2010.11.015

Hvelplund, F. (2001). Political prices or political quantities. New Energy, 5(2001), 18-23.

Jacobsson, S. (2008). The emergence and troubled growth of a 'biopower' innovation system in Sweden. Energy Policy, 36(4), 1491-1508. doi:10.1016/j.enpol.2007.12.013

Jacobsson, S., Bergek, A., Finon, D., Lauber, V., Mitchell, C., Toke, D., and Verbruggen, A. (2009). EU renewable energy support policy: Faith or facts? Energy Policy, 37(6), 2143-2146. doi:10.1016/j.enpol.2009.02.043

Jenner, S., Groba, F., and Indvik, J. (2013). Assessing the strength and effectiveness of renewable electricity feed-in tariffs in European Union countries. Energy Policy, 52, 385-401. doi:10.1016/j.enpol.2012.09.046

Kydes, A. S. (2007). Impacts of a renewable portfolio generation standard on US energy markets. Energy Policy, 35(2), 809-814. doi:10.1016/j.enpol.2006.03.002

Lancker, K., and Quaas, M. F. (2019). Increasing marginal costs and the efficiency of differentiated feed-in tariffs. Energy Economics, 83, 104-118. doi:10.1016/j.eneco.2019.06.017 
Lauber, V., and Mez, L. (2004). Three decades of renewable electricity policies in Germany. Energy \& Environment, 15(4), 599-623. doi:10.1260/0958305042259792

Lesser, J. A., and Su, X. (2008). Design of an economically efficient feed-in tariff structure for renewable energy development. Energy Policy, 36(3), 981-990. doi:10.1016/j.enpol.2007.11.007

Lipp, J. (2007). Lessons for effective renewable electricity policy from Denmark, Germany and the United Kingdom. Energy Policy, 35(11), 5481-5495. doi:10.1016/j.enpol.2007.05.015

Mabee, W. E., Mannion, J., and Carpenter, T. (2012). Comparing the feed-in tariff incentives for renewable electricity in Ontario and Germany. Energy Policy, 40, 480-489. doi:10.1016/j.enpol.2011.10.052

MacGill, I. (2010). Electricity market design for facilitating the integration of wind energy: Experience and prospects with the Australian National Electricity Market. Energy Policy, 38(7), 3180-3191. doi:10.1016/j.enpol.2009.07.047

May, N. (2017). The impact of wind power support schemes on technology choices. Energy Economics, 65, 343-354. doi:10.1016/j.eneco.2017.05.017

Menanteau, P., Finon, D., and Lamy, M. (2003). Prices versus quantities: choosing policies for promoting the development of renewable energy. Energy Policy, 31(8), 799-812. doi:10.1016/s0301-4215(02)00133-7

Meyer, N. (2003). European schemes for promoting renewables in liberalised markets. Energy Policy, 31(7), 665-676. doi:10.1016/s0301-4215(02)00151-9

Meyer, N. (2007). Learning from wind energy policy in the EU: lessons from Denmark, Sweden and Spain. European Environment, 17(5), 347-362. doi:10.1002/eet.463

Mitchell, C., Bauknecht, D., and Connor, P. M. (2006). Effectiveness through risk reduction: a comparison of the renewable obligation in England and Wales and the feed-in system in Germany. Energy Policy, 34(3), 297-305. doi:10.1016/j.enpol.2004.08.004

Morthorst, P. E. (2000). The development of a green certificate market. Energy Policy, 28(15), 1085-1094.

Munksgaard, J., and Morthorst, P. E. (2008). Wind power in the Danish liberalised power market-Policy measures, price impact and investor incentives. Energy Policy, 36(10), 3940-3947. doi:10.1016/j.enpol.2008.07.024

Nicolini, M., and Tavoni, M. (2017). Are renewable energy subsidies effective? Evidence from Europe. Renewable and Sustainable Energy Reviews, 74, 412-423. doi:10.1016/j.rser.2016.12.032

Oikonomou, V., and Mundaca, L. (2008). Tradable white certificate schemes: what can we learn from tradable green certificate schemes? Energy Efficiency, 1(3), 211-232. doi:10.1007/s12053-008-9017-7

Ragwitz, M., and Steinhilber, S. (2014). Effectiveness and efficiency of support schemes for electricity from renewable energy sources. Wiley Interdisciplinary Reviews: Energy and Environment, 3(2), 213-229. doi:10.1002/wene.85

Schallenberg-Rodriguez, J. (2017). Renewable electricity support systems: Are feed-in systems taking the lead? Renewable and Sustainable Energy Reviews, 76, 1422-1439. doi:10.1016/j.rser.2017.03.105

Schallenberg-Rodriguez, J., and Haas, R. (2012). Fixed feed-in tariff versus premium: A review of the current Spanish system. Renewable and Sustainable Energy Reviews, 16(1), 293305. doi:10.1016/j.rser.2011.07.155

Toke, D. (2007). Renewable financial support systems and cost-effectiveness. Journal of Cleaner Production, 15(3), 280-287. doi:10.1016/j.jclepro.2006.02.005

Toke, D., Breukers, S., and Wolsink, M. (2008). Wind power deployment outcomes: How can we account for the differences? Renewable and Sustainable Energy Reviews, 12(4), 1129-1147. doi:10.1016/j.rser.2006.10.021

Upton, G. B., and Snyder, B. F. (2017). Funding renewable energy: An analysis of renewable portfolio standards. Energy Economics, 66, 205-216. doi:10.1016/j.eneco.2017.06.003 
Verbruggen, A. (2009). Performance evaluation of renewable energy support policies, applied on Flanders' tradable certificates system. Energy Policy, 37(4), 1385-1394. doi:10.1016/j.enpol.2008.11.032

Wang, Y. (2006). Renewable electricity in Sweden: an analysis of policy and regulations. Energy Policy, 34(10), 1209-1220. doi:10.1016/j.enpol.2004.10.018

Winkler, J., Gaio, A., Pfluger, B., and Ragwitz, M. (2016). Impact of renewables on electricity markets - Do support schemes matter? Energy Policy, 93, 157-167. doi:10.1016/j.enpol.2016.02.049

Wood, G., and Dow, S. (2011). What lessons have been learned in reforming the Renewables Obligation? An analysis of internal and external failures in UK renewable energy policy. Energy Policy, 39(5), 2228-2244. doi:10.1016/j.enpol.2010.11.012

Woodman, B., and Mitchell, C. (2011). Learning from experience? The development of the Renewables Obligation in England and Wales 2002-2010. Energy Policy, 39(7), 39143921. doi:10.1016/j.enpol.2011.03.074

Young, D., and Bistline, J. (2018). The costs and value of renewable portfolio standards in meeting decarbonization goals. Energy Economics, 73, 337-351. doi:10.1016/j.eneco.2018.04.017

Zhou, H. (2012). Impacts of renewables obligation with recycling of the buy-out fund. Energy Policy, 46, 284-291. doi:10.1016/j.enpol.2012.03.061

\section{Appendix: A list of variables}

\begin{tabular}{|c|l|}
\hline$\pi_{i}$ & Supplier $i$ 's profit \\
\hline$p^{e}$ & Retail electricity price \\
\hline$p^{w}$ & Wholesale electricity price \\
\hline$q_{i}$ & Annual supply of electricity by supplier $i$ \\
\hline$p^{r o c}$ & Price of ROC \\
\hline$R_{i}$ & Number of ROC presented by supplier $i$ \\
\hline$\alpha$ & Obligation level set by the regulator \\
\hline$Q$ & Total supply of electricity by all suppliers \\
\hline$R$ & Total number of ROC presented by all suppliers \\
\hline$f$ & Buyout price per ROC missed \\
\hline$r$ & Recycle value awarded per ROC presented \\
\hline$r^{n}$ & Premium \\
\hline$E_{i}(r)$ & Expected recycle value \\
\hline$s_{i}$ & Marginal impact on future sales by presenting ROC \\
\hline$m$ & Profit margin \\
\hline$m s_{i}$ & Future marginal benefit \\
\hline$E_{1}\left(R_{2}\right)$ & Supplier 1's expectation of Supplier 2's presented number of ROCs \\
\hline$E_{2}\left(R_{1}\right)$ & Supplier 2's expectation of Supplier 1's presented number of ROCs \\
\hline$R^{e}$ & Total number of ROC presented at equilibrium \\
\hline $\bar{R}$ & Total number of ROC allocated \\
\hline$\beta$ & Support level by the RO scheme \\
\hline$Q^{c}$ & Estimated annual output by the renewable generator \\
\hline
\end{tabular}




\begin{tabular}{|c|l|}
\hline$\Pi^{S}$ & Renewable generator's profit from selling electricity \\
\hline$\Pi^{\text {roc }}$ & Transfer payment received by the renewable generator from selling ROC \\
\hline$Q^{g}$ & Quantity of electricity the renewable generator sold \\
\hline
\end{tabular}

